\title{
Content Strategy and Fan Engagement in Social Media, the Case of PyeongChang Winter Olympic and Paralympic Games
}

\author{
${ }^{1}$ Asli Cazorla Milla*, ${ }^{2}$ Leonardo Jose Mataruna-Dos-Santos, ${ }^{3}$ Hussein Muñoz Helú \\ ${ }^{1}$ College of Business Administration, American University in the Emirates, Dubai, United Arab Emirates. \\ ${ }^{2}$ Canadian University of Dubai, Faculty of Management, Department of Sport Management, United Arab \\ Emirates. ${ }^{3}$ Department of Economic-Administrative Sciences, Universidad Autónoma de Occidente, \\ Culiacan, Mexico, Mexico.
}

Submitted 10 July 2020; Accepted in final form 30 August 2020.

\begin{abstract}
Background. This paper investigates the pillars of content strategy and fan engagement in social networks during 2018 PyeongChang Winter Olympics and Paralympics. Objectives. The purpose of this paper is to seek reasons behind the differences in fan engagement in social media channels of PyeongChang Winter Olympics and Paralympics. Methods. Facebook and YouTube channels are used to analyze engagement and growth. Subsequent effects of fans engagement with different social media content have also been analyzed in the study. Data were collected using the Social Bakers Suite platform for the period of fifteen days of the Winter Paralympics. For the purpose of analysis 3 platforms have been used for 25 different analysis. From 25, the most significant analysis was presented in the findings. Content and sentiment analysis is used as a main research methodology. Results. The findings of this paper showed that the fans are more engaged with the contents of the Paralympic channel even though the number of followers were almost as half as the Olympics channel. The contents that were generated through marketers/organizer did not perform as well as user/fan generated content. Conclusion. This study will add to the body of academic practitioner research on social media content creation and will provide an opening for marketers to leverage social media networks for marketing communications. This cross-channel study of the Olympics and Paralympic channels found positive effects on content consumption and in the promotion of fan engagement.
\end{abstract}

KEYWORDS: Consumer Engagement, Content Strategy, Sports Marketing, Paralympic Games, Olympic Games, PyeongChang.

\section{INTRODUCTION}

The global sport management industry is one of the highest revenues generating sectors in the world. The International Olympic Committee (IOC) in the new millennium adopted as the big multinational companies the social media as a channel of communication. The rights of communication, in particular the sports broadcast and marketing rights generate a huge amount of income to the federations, committees and athletes around the world. The revenue from this non-profit organization is provided by the Olympic Games and helps athletes and develop sport worldwide. Daily, "the IOC distributes about USD 3.4 million around the world to help athletes and sporting organizations" (1). Sport mega events have become attractive to tourism, investment and broadcasting industries (2). The host city has a positive influence on the media coverage received by the neighboring cities and positions them as potential future hosts.

*. Corresponding Author:

Asli Cazorla Milla, Assistant Professor

E-mail: asli.milla@aue.ae 
The Olympic Games are not only considered as the world's top-level competition, but also the branding of the Olympic Games is recognized globally (3). The Olympic Games are staged every four years, with the summer and Winter Games alternating by being held every four years, but two years apart. Their creation was inspired by the ancient Olympic Games, which was held from the 8th century BC until the 4th century AD, and was based in Olympia, Greece. The International Olympic Committee (IOC) was established by Baron Pierre de Coubertin in the year 1894, which resulted in the first ever modern games in 1896 which was held in Athens, Greece. Currently, the IOC is the governing body responsible for the Olympic Movement, with the Olympic Charter formulating the structure as well as the authority. During the 20th and the 21st centuries, various changes have occurred to the Olympic Games due to the evolution of the Olympic Movement. These changes ensured inclusion was present as these changes included the creation of the Winter Games for snow and sports being held during the cold season, the Paralympic Games which included the people of determination, and the Youth Olympic Games which included athletes from early ages who are inspired to grow up and become future professional athletes.

The Chamonix Games were originally held as International Winter Sports Week, a meeting sponsored by the IOC, but was not considered as an official Olympic Games. The event was a success as it was well organized and included new facilities, which led the IOC to amend its charter in 1925, thus establishing what we know now as the Winter Games. Chamonix was thereafter recognized as the first Winter Olympics. 250 athletes representing 16 different countries attended the games, competing in 16 events. The PyeongChang Olympic Games occurred 94 years later. The PyeongChang Olympic Games included ninety-two different countries competing, which was the record number of most countries competing in the Winter Games. Moreover, the total number of athletes competing in The PyeongChang Olympic Games was 2,952, from which $43 \%$ were women athletes (4).

PyeongChang's vision for the 2018 Olympic Games included offering new horizons for the winter sports as well as for the Olympic Movement, the vision included a legacy which was never seen before in terms of new growth and new potential for the future. Their Olympic Plan was one of the most thought out and wellorganized plans in Olympic history, it offered a one-of-a-kind stage in which the best athletes from all over the world could achieve superior performances. The 2018 Olympic Winter Games exposed the new generations of athletes that acquire potential to the power of which the winter sports poses, due to the fact that PyeongChang acquires a strategic position in Asia of which they have access to the young and the fast growing market (1).

The 2018 Winter Olympic Games in PyeongChang strengthened the importance of acquiring social media platforms during any major sports events. Through world renown platforms such as Twitter, Instagram, Facebook and YouTube, the partners, organizations, athletes and teams were not only capable of controlling their own narrative, but also they were able to provide an interactive insight into their time spent during the games. This resulted in the increasing engagement from the fans which were able to thoroughly follow up with the athletes and teams, leading to a more immersive experience.

\section{LITERATURE REVIEW}

Social Media Marketing and Engagement. Having a social media presence has become the norm in this era and as far as millennials continue to be influenced by social media trends and even acquire news from such channels, social media marketing is a powerful way for companies of all sizes to reach customers and engage with their audience/fans/clients and potential customers. Social media has indeed created a different and new style of communication, and there are now billions of conversations happening online. People are discussing trending news, various articles, they're sharing photos of their life, and even engaging with brands. For the last decade, many researches tried to find factors that would trigger the engagement or reach more audience with a viable social media marketing strategy. Engagement is usually associated with customers' behavioral expression towards brands and it has been accepted as one of the most important key performance indicators in the customer social media research $(5,6)$ mentioned that the social media marketing and engagement works well using mega sport events.

Content Marketing and Engagement. "Quality content that is engaging and triggers conversations is today considered the most 
powerful tool in building relationships and brand awareness. The foundation of any successful content marketing strategy is based upon a clear vision of the business objective. It will help to create content that engages customers and leads to conversions for better ROI over the long term", (7) Forming content in social media is not limited to only journalists, reporters and organizations small or big and public or private. Anybody with an average computer knowledge, can share his ideas, experience, picture, video and everything he creates with others (8). The power of usergenerated content has been proven to be one of the most powerful and engaging tools in marketing (9). Alternatively, in their recent research (10), examined the impact of marketer generated content and found out that affiliative content triggers the autonomous motivation through the satisfaction of basic psychological needs which leads to user engagement (10).

Marketing in Olympics Games. Overall, Olympics Marketing is a great opportunity for marketers because it attracts viewers from all over the world. Pre-social media era, TV was a great source for Olympics Marketing and was often reserved for top advertisers. Companies were competing to get the best spot during the air commercials due to the huge audience. Many researches have proven the fact that buying ads does not guarantee the fact that it will have a positive after effect $(11,12)$. Social media has proved itself to be one of the most engaging ways to communicate with the audiences, especially amongst the millennials and Gen $\mathrm{Z}$. The young sports audience is particularly interested in being engaged with sporting events such as Esports. Recently, there is a significant increase in the occasional viewers of Esports audience with more than $25 \%$ new costumers comparing 2018 and 2021, which makes it a great platform for brands to engage with their consumers (13). Therefore, marketers and content creators must prepare themselves for Asian Games 2022 to monetize the content efforts.

PyeongChang Olympics Social Media Statistics. We have seen a pattern in social media during the Olympics in PyeongChang. Compared to the last years, social media content was shorter and more inclined to show the behind the scenes of the Olympic Games. The target group to engage was Millennials and Generation $\mathrm{Z}$ in opposition to Sochi Olympics 2014. PyeongChang 2018 was also the biggest Olympic Winter Games ever on social media platforms, with official content consumed by 300 million users, resulting in over 1.6 billion video views. (14). According to the report that was published by the Burson Cohn \& Wolfe Sports Practice(BCW) 50,000 new fans in one day followed the @Olympics Twitter due to the K-POP band EXO's performance during the Closing Ceremony (15). Digital users had unique access to the games more than 1800 hours of live streaming coverage. When we analyze the engagement data from February 2017 through January 2018 we can see that a drastic increase has observed from November 2017 onwards. On March 2017, the social media engagement rates were about 2M where in Janu 2018 the engagement reached to $3.5 \mathrm{M}$. (16).

It is interesting to see a similar pattern in the social media channels of the country teams. Most of the engagement and the interaction came from Instagram pages. Photos were the most consumed content, videos being the runner-up after the photos. It was also obvious to state that frequency did not necessarily correlate to the engagement, so the quality content beats the quantity (17). So marketing practitioners must focus on creating quality content rather than feeling up the feeds. Some channels like PyeongChang 2018 had a $25 \%$ increase in their followers, whereas IOC saw a very little increase of $1.9 \%$. (Table 1 ).

Research Problem. The Olympic Games was considered during many years as the world's most lucrative sports event. Other competitors divide the market such as FIFA World Cup, XGames, Premier League, UEFA Cup, Bundesliga, La Liga and the American Sport Leagues such as NBA, NFL, MBL and NHL (Table 2). For FIFA the revenue growth from the previous cycle in USD 888 million, specific to, the television broadcast rights are responsible per $49 \%$ of the income. The TV rights in the full cycle revenue (2015-2018) amounted USD 3.127 million, overpassing 21\% from the previous cycle (19). Observing the Figure 1, the revenue for the Olympiad that spans 2013 to 2016, covering the Olympic Winter Games Sochi 2014 and the Olympic Games Rio 2016, was USD 5.7 billion (1). Compared with the FIFA Revenue in the cycle 2015-2018 in Figure 2, the IOC presented less income from the market rights. Nonetheless, it is not clear the revenue from the social media channels operated for the mega events. 
Table 1. Winter Olympics 2018, National Committee Social Media Channels Performance- Developed by the Authors Based on the Data by Hookit (18)

\begin{tabular}{|c|c|c|c|c|c|c|}
\hline Organization & $\begin{array}{c}\text { Total } \\
\text { Followers }\end{array}$ & $\begin{array}{l}\text { Followers } \\
\text { Growth }\end{array}$ & Posts & $\begin{array}{c}\text { Total } \\
\text { Interactions }\end{array}$ & $\begin{array}{c}\text { Interactions } \\
\text { Per Post }\end{array}$ & $\begin{array}{c}\text { Internet } \\
\text { Penetration in } \\
\text { the country }\end{array}$ \\
\hline $\begin{array}{c}\text { International } \\
\text { Olympic Committee } \\
\text { (IOC) }\end{array}$ & $27,110,345$ & $1.9 \%$ & 1,213 & $50,914,887$ & 41,974 & N/A \\
\hline PyeongChang 2018 & $1,102,771$ & $25.7 \%$ & 1,401 & $7,495,576$ & 5,350 & N/A \\
\hline Team Canada & $1,971,947$ & $9.1 \%$ & 4,379 & $21,352,280$ & 4,876 & $34.56 \mathrm{M}$ \\
\hline Team USA & $6,692,805$ & $3.6 \%$ & 2,458 & $14,804,850$ & 6,023 & $312 \mathrm{M}$ \\
\hline $\begin{array}{c}\text { France national } \\
\text { olympic committee }\end{array}$ & 607,179 & $5.0 \%$ & 560 & $2,738,454$ & 4,890 & $52.3 \mathrm{M}$ \\
\hline $\begin{array}{l}\text { Deutscher } \\
\text { olympischer } \\
\text { sportbund }\end{array}$ & 354,917 & $13.3 \%$ & 131 & $3,504,504$ & 36,752 & $72 \mathrm{M}$ \\
\hline Team GB & $2,850,224$ & $1.0 \%$ & 1,163 & $7,968,391$ & 6,852 & $41.8 \mathrm{M}$ \\
\hline $\begin{array}{c}\text { Japan national } \\
\text { olympic committee }\end{array}$ & $1,173,576$ & $8,9 \%$ & 430 & $2,217,915$ & 5,158 & $101 \mathrm{M}$ \\
\hline
\end{tabular}

Table 2. Competitors of IOC with the Highest Revenues Worldwide Source: Developed by the Authors, Based on Data of Parker (20)

\begin{tabular}{lc}
\hline Sport League & Revenues 2018 - values in US Dollars \\
\hline Nippon professional baseball (Japanese baseball league) & $\$ 1.1$ billion \\
Ligue 1 (France/Monaco football league) & $\$ 1.5$ billion \\
Serie A (Italian football league) & $\$ 1.9$ billion \\
La Liga (Spanish Football league) & $\$ 2.2$ billion \\
Bundesliga (German football league) & $\$ 2.8$ billion \\
National hockey league (NHL) & $\$ 3.7$ billion \\
National basketball association (NBA) & $\$ 4.8$ billion \\
Premier league (english/welsh football Lleague) & $\$ 5.3$ billion \\
Major league baseball (MLB) & $\$ 10.3$ billion \\
National league football (NFL) & $\$ 13$ billion \\
\hline
\end{tabular}

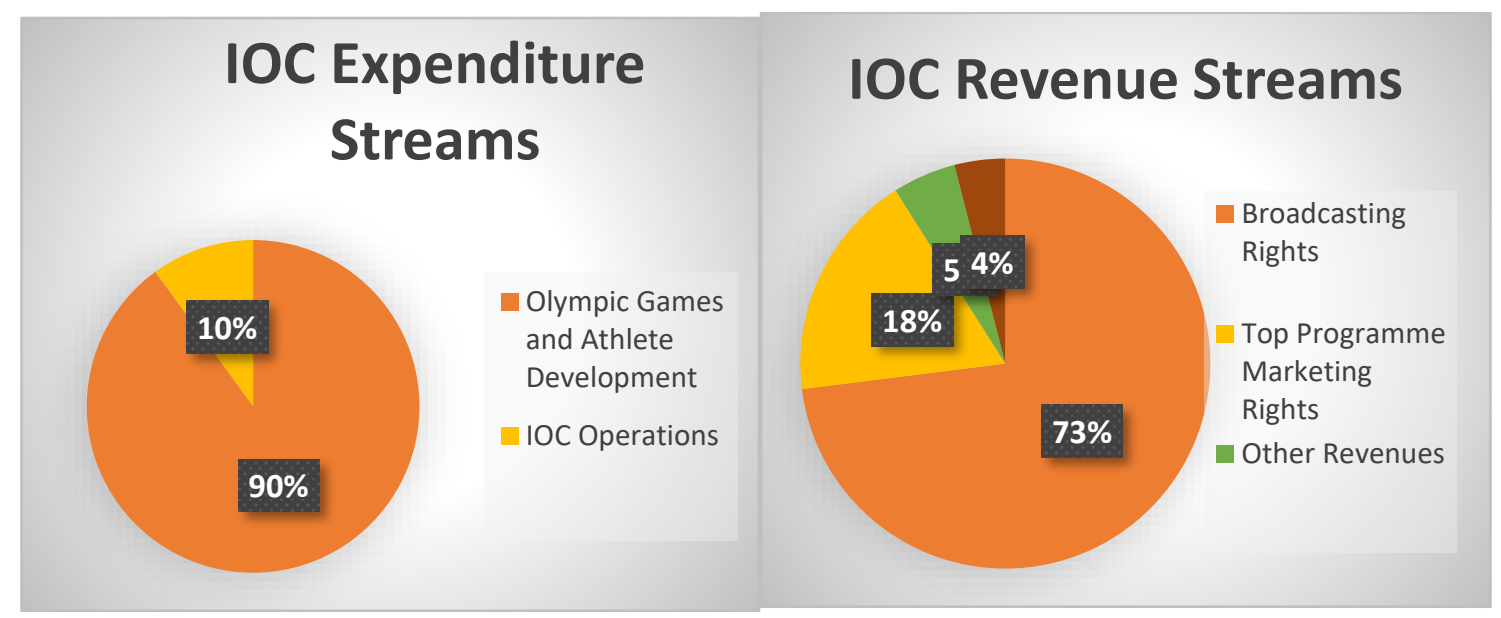

Figure 1. Distribution to Sport and Athlete Development Across the Globe. Adapted from IOC, 2019 (1)

FIFA (19) declares that years hosting the World Cup the revenue reflects an increment of $1000 \%$ in the television broadcasting rights and around $800 \%$ of the marketing rights. Those values are not declared by the IOC and present some difficulties to compare summer and winter events.

In addition to the above broadcasting and marketing problems, another important issue is the fan engagement and the content strategy 
which is employed in the social media channels. Scholars have been arguing about the social media engagement and the impact of the interactions for almost a decade. Yet, a conclusion has not been made at this point. Content strategy has a very simple yet challenging to execute definition. It is the art of communicating the right content to the right persons at the right place, right time and the right context. During PyeongChang Games it was noticed that the content strategy of Olympic and Paralympic Channels were not structured as it should have been, therefore it did not resonate with the audience at the expected level.

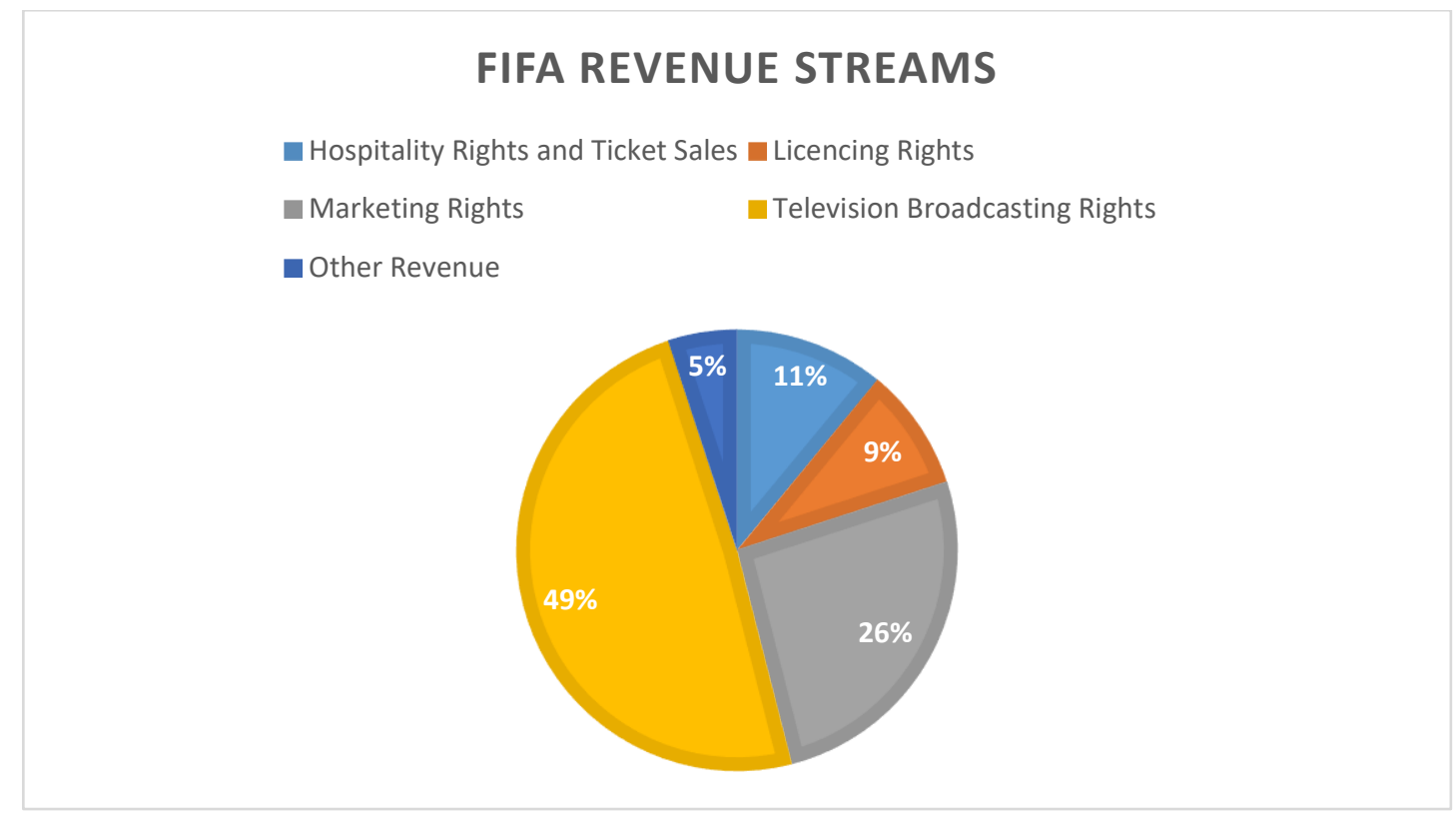

Figure 2. FIFA Revenue 2015-2018 (US Dollars Million) Source: (19).

Data Collection and Analysis. For the analysis, data were collected using the Social Bakers Suite platform for the period of fifteen days of the Winter Paralympics. Twitter, Facebook and YouTube were subject to the analysis as social media platforms. The analysis of significantly important posts is discussed in this section.

Metrics that are mentioned in the analysis are explained briefly below.

Number of Interactions per 1000 Fans

Every post has the metric Number of interactions per 1000 fans that identifies how engaging the post is. It is the sum of interactions (reactions, comments and shares divided by the number of fans a page has on the day of the posts and multiplied by 1000 .

Number of Interactions

The number of interactions during a selected time range.

Number of Reactions

The number of reactions during a selected time range.

Color Scheme

Olympics Channel: Navy Blue

\section{Paralympics Channel: Green}

Facebook Analysis. We have observed that the average number of interactions per day during the Olympic games channel was 9.274 whereas in the Paralympic Channel was 19.260. Prior to Olympics start, both channels have nearly the half of the interactions on a daily basis compared to the interactions gained during PyeongChang Winter Olympics. When these numbers are cross analyzed with the number of followers in each channel, we have seen that the interaction and engagement in the Paralympic Channel was significantly higher than the Olympic Channel.

Secondly, we have analyzed the type of posts that was published however we wanted to see the leverage point to understand the content strategy therefore the time frame was set to $23 \mathrm{rd} \mathrm{Feb}$ to $23 \mathrm{rd}$ May 2018.For both channels, videos were dominant making up more than $55 \%$ of the total content types. Evidently, Paralympic Channels used links to direct fans to several pages of Paralympic Channels whereas Olympic Channels have not used this strategy. Instead, they focused on photos. (Figure 6). 


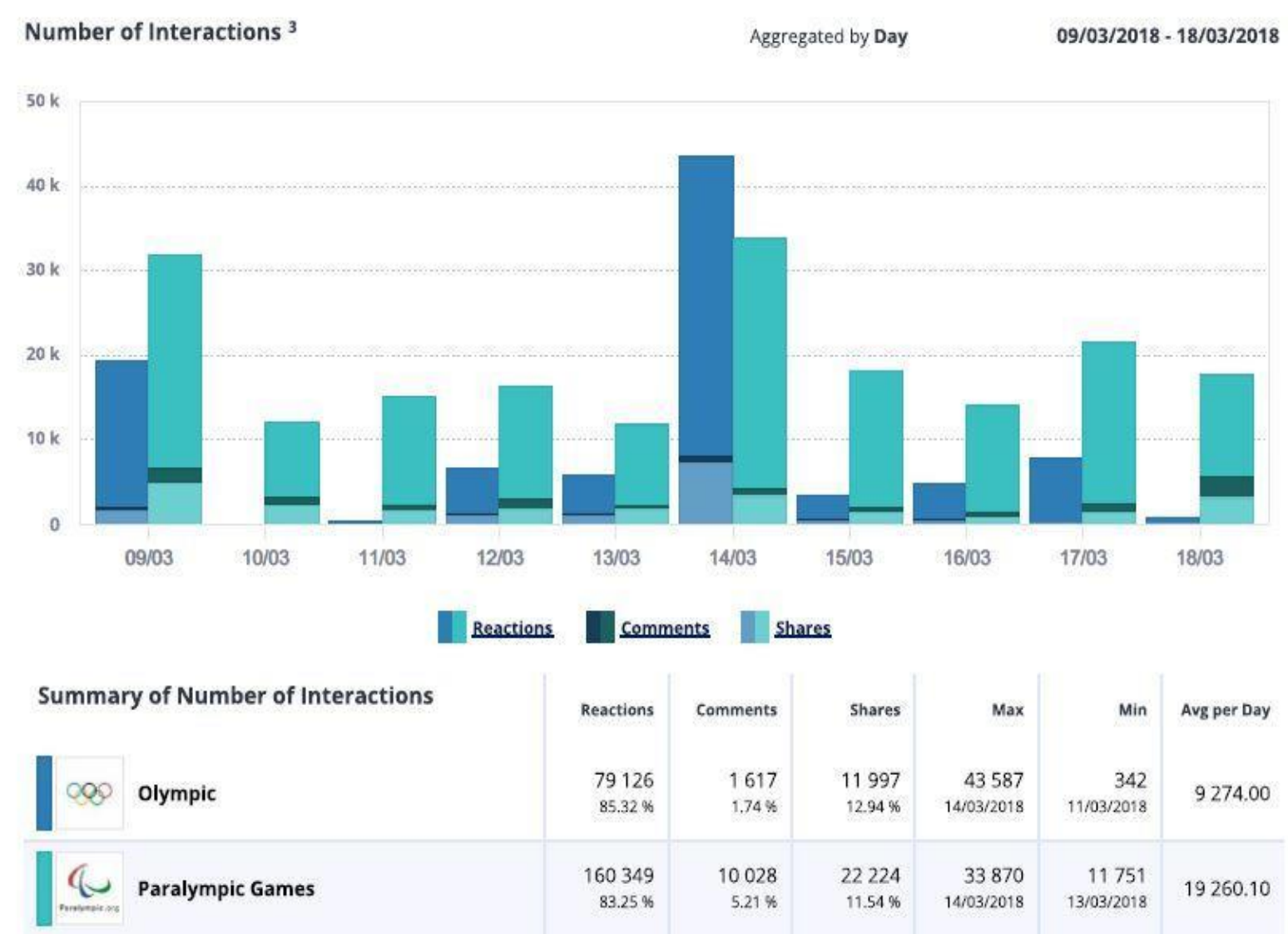

Figure 3. The Number of Interactions by Reactions Comments and Shares During the Period of 9/03/2018-18/03/2018
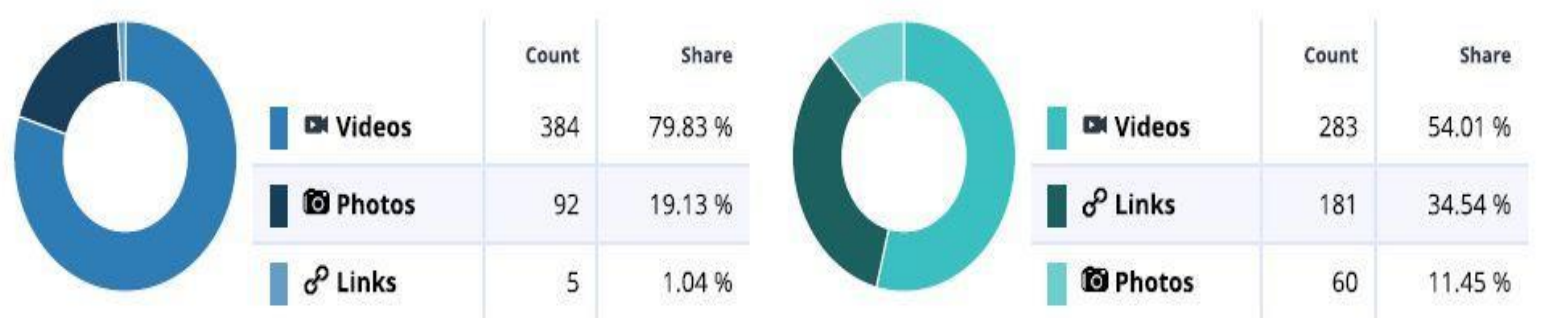

Figure 4. Distribution of the Post Types During the Period of 23/02/2018-23/05/2018

Later we have analyzed the most engaging promoted and organic posts in the Paralympic Channels for the same period and found out that there was no big difference between organic vs promoted posts. In fact, there were more comments in the Organic post than the Promoted post. What was interesting to see is the content type that was created. It was a "behind the scenes" user generated blogger post that resonated with the audience.

Figure 7 shows that in both the Paralympic Channels and Olympic channels the majority of the interactions came from the organic posts rather than the promoted posts. Marketer generated content was also performing well in the Olympic Games, Olympic-related post of all the partners across the period of the Games, with a 
Facebook video post of its winter Olympic drone cameras following its team's journey to the opening ceremony in PyeongChang. (Figure 8)

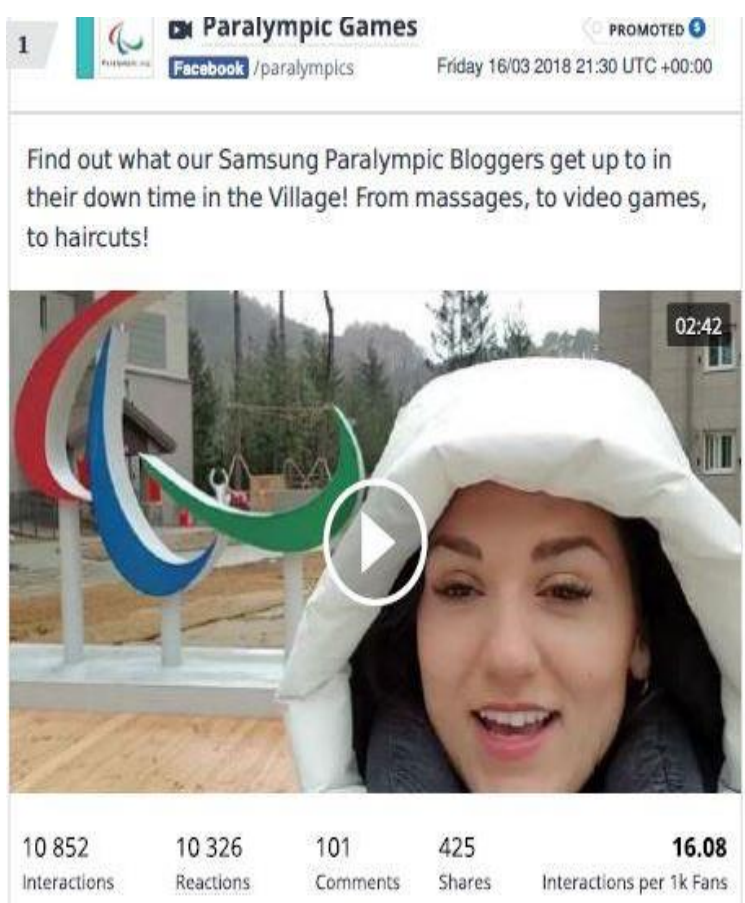

Figure 5. Most Engaging Promoted Post-Published Date

The data showed that the reactions of the fans were mostly positive. The comments were dominantly positive in both channels expressed with Like and Love buttons on Facebook. The reactions that Paralympics got were more than double than the Olympics Channel (Figure 9).

YouTube Analysis. When we analyzed YouTube, we saw a similar scenario. The Paralympics Channel performed well on this
The reputation of the opening ceremony combined with the striking visuals contributed to the appeal of the post.

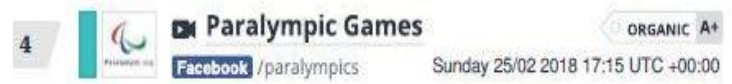

In case you've been completely absorbed by the Olympic action and are unsure what to watch next; let Bandabi whet your appetite for the Paralympics! We are 12 days away! $\mathrm{CD}$

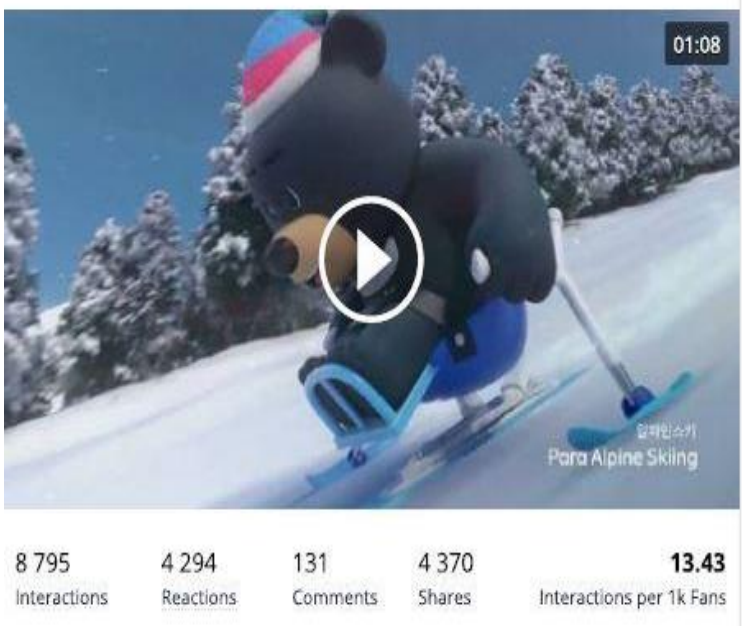

Figure 6. Most Engaging Organic Post-Published Date

platform compared to the Olympic Channels. The interaction number was almost double in the Paralympic Channels compared to Olympic Channel. (Figure 10).

However, the Olympic Channel attracted many people with the video of K-Pop boy Band EXO on the Closing Ceremony. Not surprisingly, the most interacted post on Olympic Channel was the performance of the group.

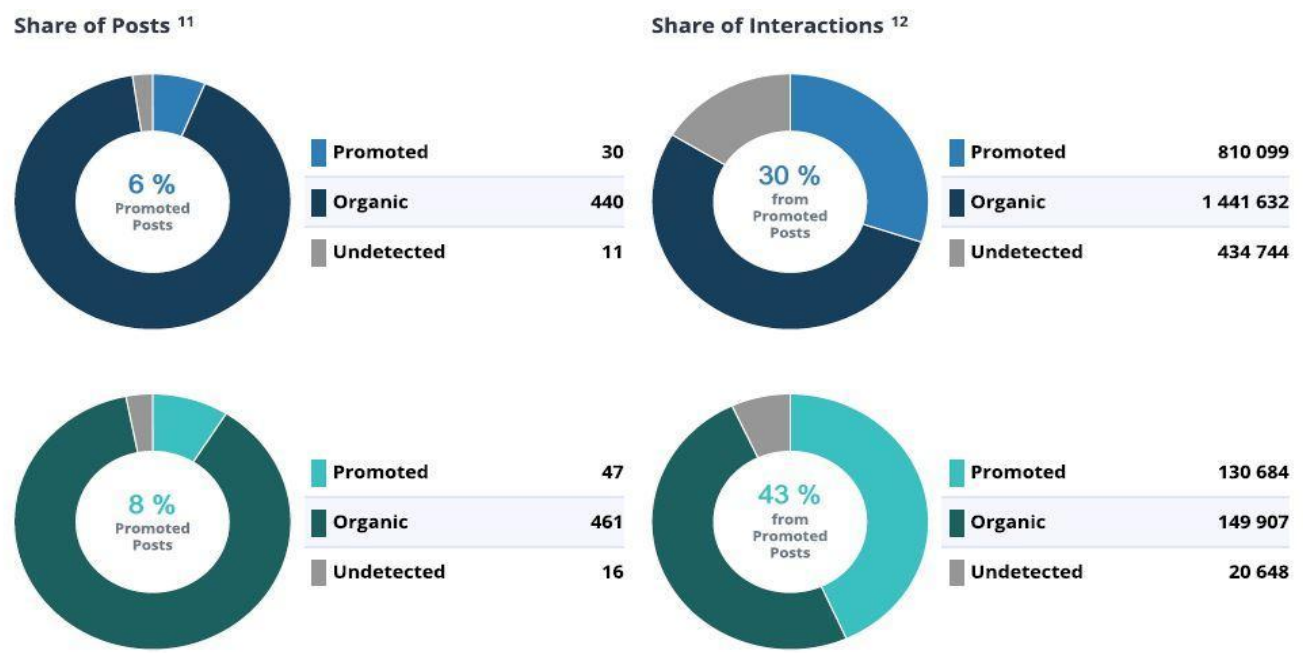

Figure 7. Share of Interactions and Posts by Promoted and Organic - Time Period 23/02/2018-23/05/2018 


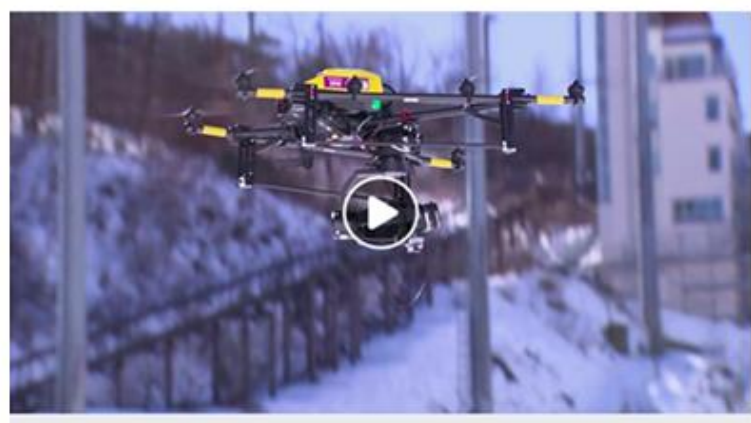

inter 0

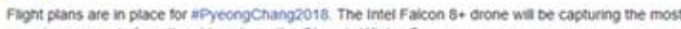
amazing moments from the sbes above the Olymoic Winter Games.

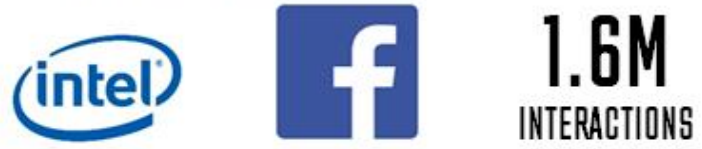

Figure 8. Market Generated Content-Intel-Olympic Games-Source: Sportcal (20)

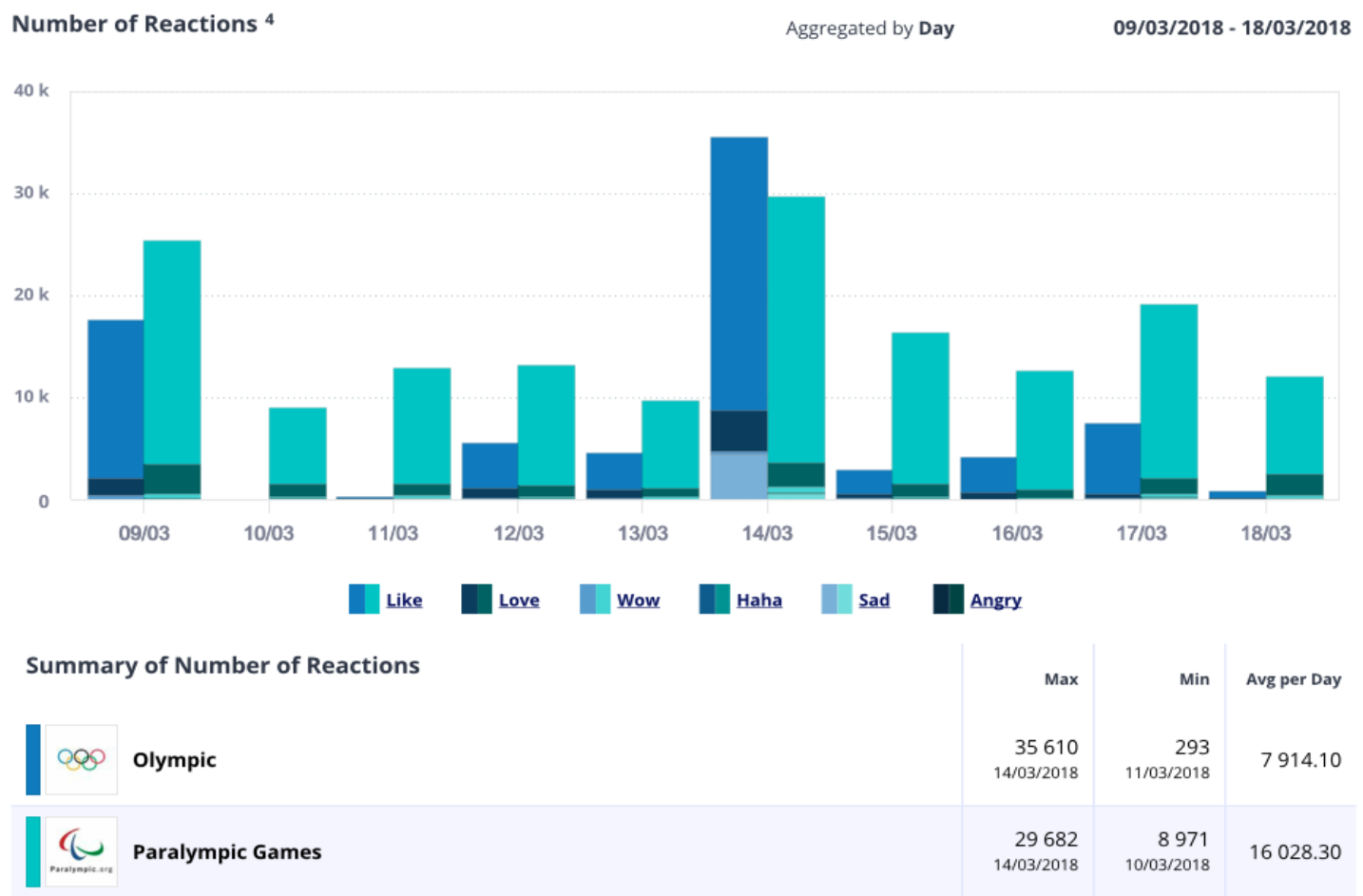

Figure 9. Number of Reactions with Sentiment-Period of 09/03/20018-18/03/2018 
Number of Interactions per 1000 Subscribers $^{6}$

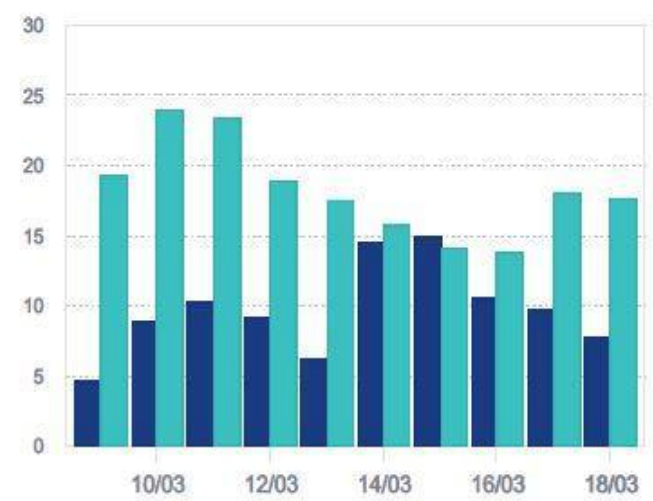

Aggregated by Day

Max Interactions per 1000 Subscribers

14.90

$15 / 03 / 2018$

Min Interactions per 1000 Subscribers

4.62

$09 / 03 / 2018$

Sum of Interactions per 1000 Subscribers per Period

96.46
09/03/2018 - 18/03/2018

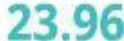

$10 / 03 / 2018$

13.82

$16 / 03 / 2018$

Figure 10. Number of Interactions per 1000 Subscribers-Period of 09/03/20018-18/03/2018
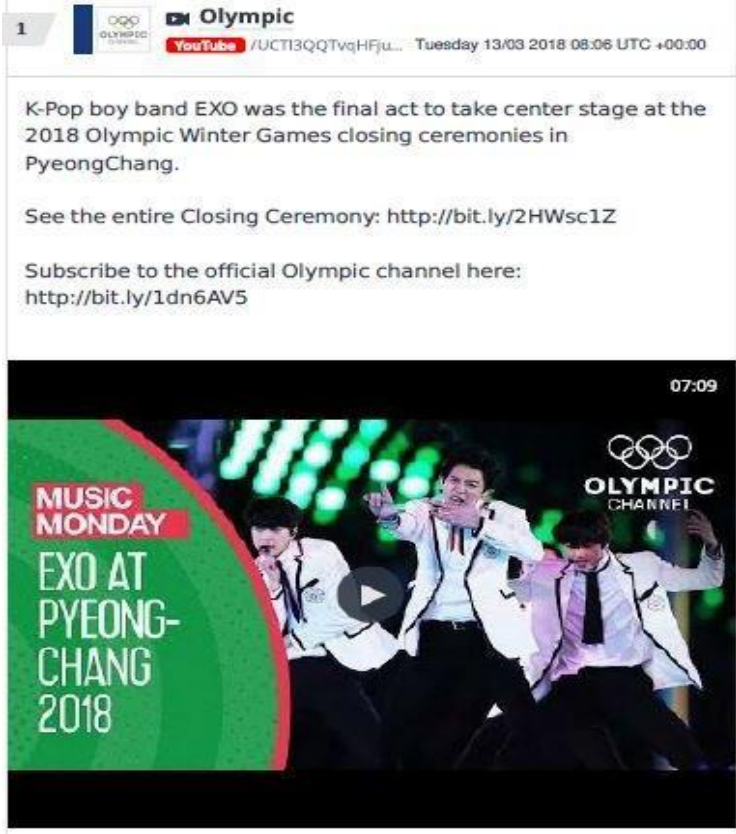

$\begin{array}{llll}154277 & 143090 & 1729 & 9458 \\ \text { interactions } & \text { Likes } & \text { Dislikes } & \text { Comment }\end{array}$

Figure 11. YouTube Most Interacted Post-Olympics

\section{MATERIALS AND METHODS}

Sentiment analysis is known as the technique of using interpreting the emotions expressed in a text by someone, such as reviews or comments in social media platforms. Sentiment analysis or opinion mining is conducted by following many types and approaches of algorithms, Natural Language Processing (NLP), and Data Science (21). At the most fundamental level, the task is performed by taking a piece of text such as a

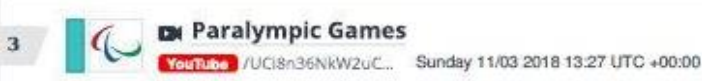

PyeongChang 2018 Paralympic Winter Games full Opening Ceremony! Subscribe to our channel and be the first to watch all the action from PyeongChang. Official website:

www. Paralympic.org

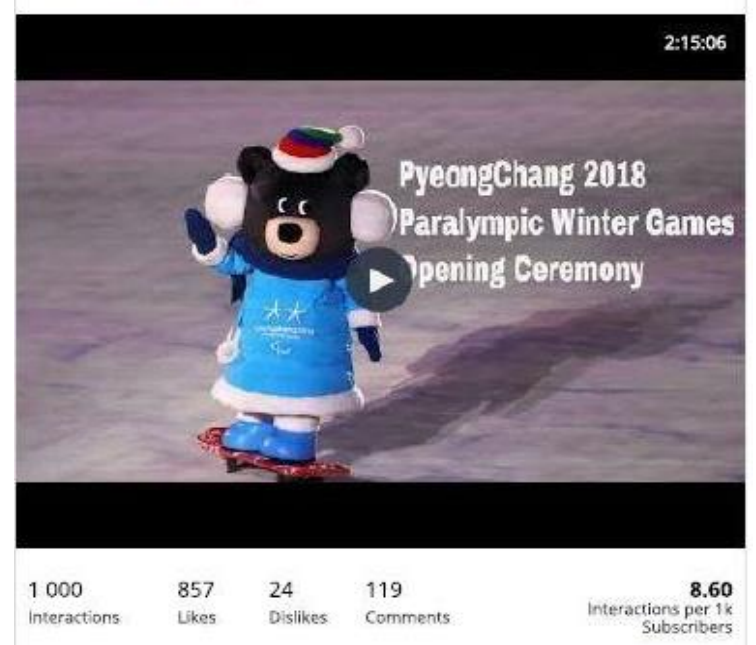

Figure 12. YouTube Most Interacted Post -Paralympics

review or post, and then the analyst automatically scores it for the opinions and sentiments contained within the text to further understand the reviewer's emotions when giving the review. In this research sentiment analysis was used to evaluate the number of likes, retweets, or reply to determine the interaction factors of the users. (22). In this study, we have based our theoretical framework on the basis of sentiment and content analysis to analyze the most engaging posts in the 
Olympic and Paralympic Channels. The following formula was considered as base for understanding the engagement rate.

Engagement Rate Formula.

Engagement Rate (\%)

$=\left(\frac{\text { Likes }+ \text { Comments }+ \text { Shares }}{\text { Total Followers }}\right) \times 100$

\section{DISCUSSION AND CONCLUSION}

Every year, prior to the event, the International Olympic Committee (IOC) releases a comprehensive list of social media rules concerning the event. "The International Olympic Committee (the "IOC") encourages accredited persons at the XXIII Olympic Winter Games PyeongChang 2018 (the "Games") to share their experiences with their friends, family and supporters via social and digital media. These guidelines (the "Guidelines") are designed to ensure that these activities respect the Olympic values and the rights of others" (23). While developing a content strategy, these guidelines must be taken into serious consideration as these are set regulations by IOC. The Asian games featured esports firstly in 2018 and in 2022 the event is expected to be the second largest transnational sporting competition after the Olympics Games. Millennial viewers are ready to reengage with the sports with the entry of these games. It is undoubtedly a significant platform for awareness and participation. A recent metaanalysis by Think With Google of 56 case studies across eight countries proved that advertising on YouTube delivered a higher ROI than TV in nearly 80 per cent of cases. Therefore, it is crucial to understand the effect of YouTube and it is important to make the broadcasting free for all the users for next Olympic games. By doing so, companies can leverage the advertising budgets and get return on investments which will result in beneficial for Olympic Games. The results of the social media content and the engagement has proven that Paralympics Games have created stronger interactions compared to the Olympics since they affect the fans with emotional sentiments. The decision to have live broadcast to the games on social media, makes the Paralympic games more attractive in the digital platforms. Summer Olympics 2020 will be the first Olympics that will have online and free broadcasting. Having this real-time advantage in-mind, the brands can leverage the newer social media channels such as TikTok or Lasso by Facebook.

Another major finding of the analysis was it is crucial to connect with the fans directly rather than pushing the content without meaningful connections. Being thoughtful and having the tone of empathy is especially important when posting in Paralympics Channel. Content strategies for sporting events social media channels should be carefully designed considering the type of posts, the source of the content to maximize the engagement. Metrics such as engagement rate and views per post is important to understand the impact of the social media efforts during Olympics. Sport marketers need to concentrate on a mix of user and marketer generated content in or-der to attract more sponsorships.

Our findings corresponded with the new marketing strategy of IOC. With the postpone of Tokyo Olympics 2020, The International Olympic Committee (IOC) has decided to digitalize its marketing efforts with the \#StrongerTogether' campaign in an attempt to connect the Olympics audience through personalization and localisation both during the games and post event. Digital Engagement Marketing Manager Christopher Carroll identifies the new content approach as 'people centric' and emphasizes the importance of user generated content for better fan engagement in social media (24).

The PyeongChang Olympics made a significant impact on the new media platforms and content strategies. Marketers and content strategists must consider the type of posts, the source of the content and the organic vs promoted posts if they wish to remain at the top of the engagement game. Not only this model will be applicable for mega-events but also can be applied for sports club in conjunction with the previous researchers findings (25). After analyzing the social media posts of both Paralympics and Olympics Channels we propose the following framework to have a strong content strategy. Theoretical framework will contribute to the body of content marketing strategy in specific to sports industry. Sports marketers and advertisers will benefit from the analysis of the results for future content strategies. 


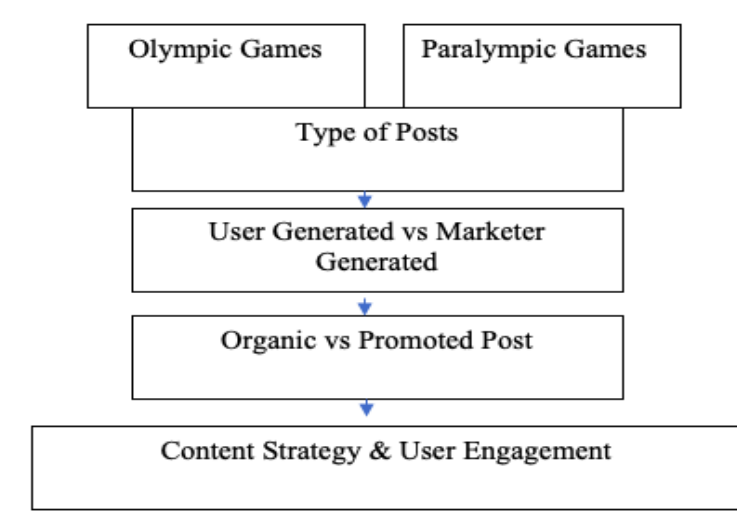

Figure 13. Developed by Authors- Proposed Theoretical Framework for Future Research

Limitations and Future Research. This research mainly focuses on the few social media channels in a short period of time. For this reason, one step forward to this research is to analyze various timelines and multiple social media channels at the same time to see their real time growth and engagement rates. Understanding different content types play a key role in channel selection. Despite the conclusions about links between content strategy and the factors affecting it the research presents certain limitations with respect to theoretical questions, as well as to methodological issues. The research heavily relies on the aggregated and processed data. It will be more valid if real time data could be collected and then processed for a longer period of time. After the Summer Olympics 2020 which will take place in Tokyo, our aim is to make a more comprehensive and comparative study with more reliable and real time sources of data. Other limitations of this research are similar to other investigations in social media are the restriction of USA based social media platforms in other countries. The seasonality of the events, the pre and post event period and the off periods are volatile and fragile to generalize the impacts of the social media performance. The countries, the consumer behavior, the culture, the religious aspects, the restriction of access to the digital platforms, the political current during the games are other important variables that will affect and ultimately change the content strategy. Therefore, our objective is to make a more empirical research considering all these factors.

\section{APPLICABLE REMARKS}

- Content strategies for sporting events social media channels should be carefully designed considering the type of posts, the source of the content to maximize the engagement.

- Metrics such as engagement rate and views per post is important to understand the impact of the social media efforts during Olympics.

- Sport marketers need to concentrate on a mix of user and marketer generated content in order to attract more sponsorships.

\section{REFERENCES}

1. IOC. How the IOC finances a better world through sport. 2020. Available from: www.olympic.org/funding.

2. Shinke RG, Hanrahan SJ. Sport for development, Peace and Social Justice. Morgantown2012.

3. Ploquin P. Branding lessons from the Olympic Games 2016. Available from: https://medium.com/greaterthan/branding-lessons-from-the-olympic-games-6b51fac7e0fc.

4. Settimi C. By The Numbers: The 2018 Pyeongchang Winter Olympics. 2020. Available from: https://www.forbes.com/sites/christinasettimi/2018/02/08/by-the-numbers-the-2018-pyeongchang-winterolympics/\#5a05478d7fb4.

5. Ma L, Sun B, Kekre S. The Squeaky Wheel Gets the Grease-An empirical analysis of customer voice and firm intervention on Twitter. Market Sci. 2015;34(5):627-645. doi: 10.1287/mksc.2015.0912

6. Mataruna-Dos-Santos LJ. The Intentions of International Tourists to Attend the 2016 Rio Summer Olympic and Paralympic Games: A Study of the Image of Rio de Janeiro and Brazil. Ann Appl Sport Sci. 2020;8(3). doi: 10.29252/aassjournal.798

7. Jannsen K. Running a Super-Effective Inbound Marketing Campaign The Ultimate Guide 2018. Available from: https://blog.arcsncurves.com/blog/ultimate-guide-running-inbound-marketing-campaign-uae.

8. Milla AC. Mataruna-Dos-Santos LJ. Social media preferences, interrelations between the social media characteristics and culture: a view of Arab nations. Asian Social Science. 2019;15(6):71-77. doi: 10.5539/ass.v15n6p71

9. Barger V, Peltier JW, Schultz DE. Social media and consumer engagement: a review and research agenda. $J$ Res Interactive Market. 2016;10(4):268-287. doi: 10.1108/JRIM-06-2016-0065

10. Weiger WH, Wetzel HA, Hammerschmidt M. Who's pulling the strings? The motivational paths from marketer actions to user engagement in social media. Europe J Market. 2019;53(9):1808-1832. doi: 10.1108/EJM-10-20170777 
11. Pham MT, Johar GV. Market prominence biases in sponsor identification: Processes and consequentiality. Psychol Market. 2001;18(2):123-143. doi: 10.1002/1520-6793(200102)18:2<123::AID-MAR1002>3.0.CO;2-3

12. O'Reilly N, Nadeau J, Séguin B. In-stadium sponsorship evaluation of a mega-sponsee: the 2004 Grey Cup. Int $J$ Sport Market Sponsorship. 2007;8(2). doi: 10.1108/IJSMS-08-02-2007-B007

13. Newzoo. Global Esports Market Report 2018. Available from: https://asociacionempresarial esports.es/wpcontent/uploads/newzoo_2018_global_esports_market_report_excerpt.pdf.

14. IOC. Marketing Report 2018. Available from: https://stillmed.olympic.org/media/ Document\%20Library/OlympicOrg/Games/Winter-Games/Games-PyeongChang-2018-Winter-OlympicGames/IOC-Marketing/Marketing-Report.pdf.

15. IOC. Factsheet. International Olympic Committee. Archived from the original (PDF) on 29 April 2011. BCW Report 2011. Available from: https://bcw-sport.com/.

16. Newswhip Analytics. Newswhip Analytics 2018. Available from: https://www.newswhip.com/2018/02/socialmedia-winter-olympics/.

17. Feehan B. Rivalympics: Social Media's Answer to PyeongChang. 2018 Available from: https://www.rivaliq.com/blog/2018-rivalympics-social-medias-answer-to-pyeongchang/.

18. The Social Winter Games. Social Media Analysis on PyeongChang 2018', in partnership with Hookit 2018. Available from: https://www.sportcal.com/Insight/Features/117914?\&f=i\%3A2\%2FMedia\%7C.

19. FIFA. Financial Report 2018. Available from: https://resources.fifa.com/image/upload/xzshsoe2ayttyquuxhq0.pdf.

20. The Social Winter Games. Social media analysis on Pyeong Chang 2018. Available from: https://www.sportcal.com/Insight/Features/117914?\&f=i\%3A2\%2FMedia\%7C.

21. Monkeylearn Sentiment Analysis. Monkeylearn Sentiment Analysis 2020. Available from: https://monkeylearn.com/sentiment-analysis/.

22. Ray P, Chakrabarti A, Ganguli B, Das PK. Demonetization and its aftermath: an analysis based on twitter sentiments. Sädhanā. 2018;43(11):186. doi: 10.1007/s12046-018-0949-0

23. IOC. Social and Digital Media Guidelines for persons accredited to the XXIII Olympic Winter Games Pyeong Chang 2018. Available from: https://stillmed.olympic.org/media/Document \%20Library/OlympicOrg/Games/Winter-Games/Games-PyeongChang-2018-Winter-Olympic-Games/IOCSocial-and-Digital-Media-Guidelines/PyeongChang-2018-Social-Media-Guidelines-eng.pdf.

24. Caroll C. The Olympics' new marketing strategy: Going 'direct-to-people' 2020. Available from: https://www.marketingweek.com/olympic-marketing-digital-tokyo-2020/.

25. Seifi Salmi T, Benar N, Honari H. Identifying Value Creation Strategies in the Brand Communities of Sport Clubs Based on the Use of Social Media. Annal Appl Sport Sci. 2019;7(2):55-61. doi: 10.29252/aassjournal.7.2.55 